\title{
Rainfall Prediction using Extreme Learning Machine for Coonoor Region
}

\author{
S. Renuga Devi
}

\begin{abstract}
Rainfall time-series forecasting is an important research area which has applications in several fields like flood forecasting, drought prediction, water resource planning and management, precision agriculture and disaster management, to name a few. This paper discusses about a machine learning method called the Extreme Learning Machine (ELM) for predicting rainfall. The study area is Coonoor region, Tamil Nadu, India, which is prone to rainfall induced landslides. Two data sets have been used in this study. Data set 1 comprises of daily rainfall data of Coonoor, meteorological parameters like temperature, wind speed, relative humidity cloud cover and month, for the period 2004-2013. Data set 2 consists rainfall data of 14 rain gauge stations and month. A comparative study between the data sets is performed to show that only rainfall data is sufficient to accurately predict the rainfall in the given region. This is substantiated by performing sensitivity analysis on both the data sets. Sensitivity analysis also provides the most important predictor that contributes to accurate prediction of rainfall.
\end{abstract}

Keywords: Extreme learning machine, rainfall prediction, sensitivity analysis, single hidden layer feed forward network.

\section{INTRODUCTION}

$\mathrm{R}$ ainfall is a complex atmospheric process, dependent on several parameters that vary in space and time, which makes its accurate prediction very difficult. Rainfall prediction has many real world applications such as precision agriculture, flood and drought prevention, landslide risk assessment, reservoir operation and irrigation scheduling etc. Fig. 1 shows the distribution of annual rainfall in India.

Rainfall time series forecasting has been done extensively using feed forward neural networks due to its ability to: (1) approximate complex non-linear mappings from the input sample, (2) to provide models for large class of natural and artificial phenomena that are difficult to handle using parametric techniques [1].

Though rainfall prediction has been carried out using many ANN based algorithms especially the single hidden layer feed forward networks, the major bottlenecks faced are (1) slow learning rate because of the gradient based approach and (2) several iterations that are needed to update the weights before the least MSE is obtained. The traditional BP algorithms have several issues in their implementation, which makes it unsuitable for this particular application, which are: (1) the algorithm converges very slowly, when the learning rate is too

Revised Manuscript Received on December 02, 2019

* Correspondence Author

S. Renuga Devi *, School of Electronics Engineering, Vellore Institute of Technology Vellore, India. Email: srenugadevi@vit.ac.in.

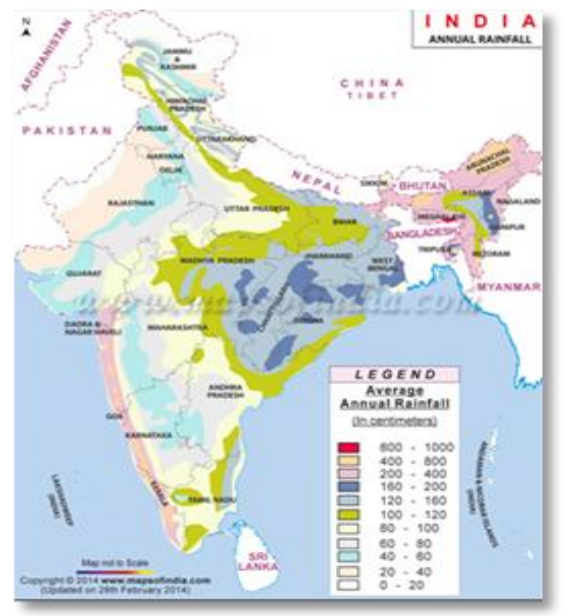

Fig. 1.Map showing annual rainfall in India

small, and when the learning rate is large, the algorithm becomes unstable and diverges. (2) The iterations may stop at a local minima [1], which is undesirable if the global minima lies far below the local minima. (3) Gradient based algorithms are very time consuming. (4) If the network is over trained then it can lead to worst generalization performance. Thus validation and suitable stopping methods have to be employed. In addition to the above, ANN models have a limited ability to account for any physics of the hydrologic processes in a catchment [2-3].

Extreme learning machine algorithm proposed by Huang et.al in 2006 was put forward as a means to overcome the major drawbacks seen in traditional learning algorithms. ELM is a single hidden layer feed forward network (SLFN) which uses the concept of empirical risk minimization [4]. ELM network gets trained in a single iteration and so is less time consuming. The algorithm avoids local minimization, reduces over fitting, and results in better generalization performance while compared to other SLFNs.

Due to the characteristics of ELM mentioned above, it has been used for several applications. In [5], the authors have proposed a method where ELM is used along with principal component analysis (PCA) for short term precipitation forecast. PCA reduces the dimensionality and makes the new predictors orthogonal to each other, thereby removing any sort of collinearity between the predictors. In [6], ELM for time series analysis is proposed. In [7] the researchers have proposed a three layer hidden neural network for time series application and found out the best number of hidden nodes that would give the most accurate prediction. 


\section{Rainfall Prediction using Extreme Learning Machine for Coonoor Region}

It was compared with the results obtained in a linear regression model. In [8], the authors have proposed an ELM model for sales forecasting in fashion retail. Thus we find that ELM and its variants have been exhaustively used for regression based models and forecasting applications. Apart from forecasting, we find that ELM has been employed for face recognition in [9]. This paper uses ELM for the purpose of daily rainfall forecasting and also studies the important atmospheric parameters that act as essential predictors.

\section{EXTREME LEARNING MACHINE}

ELM algorithm is governed by two principles:1) When the number of hidden neurons $\mathrm{N}$ and the number of training samples $\mathrm{N}$ are equal, the hidden layer parameters (the additive nodes' weights and bias) can be assigned randomly and based on this the output weights can be analytically calculated by taking inverse and realizing zero error. 2) When the number of training samples is larger than the number of hidden nodes, parameters of hidden nodes can still randomly be assigned and the output weights can be calculated by using a pseudo inverse to give a small non-zero training error [1]. Fig. 2 and Fig. 3 represent the ELM network and the flow diagram for the ELM algorithm.

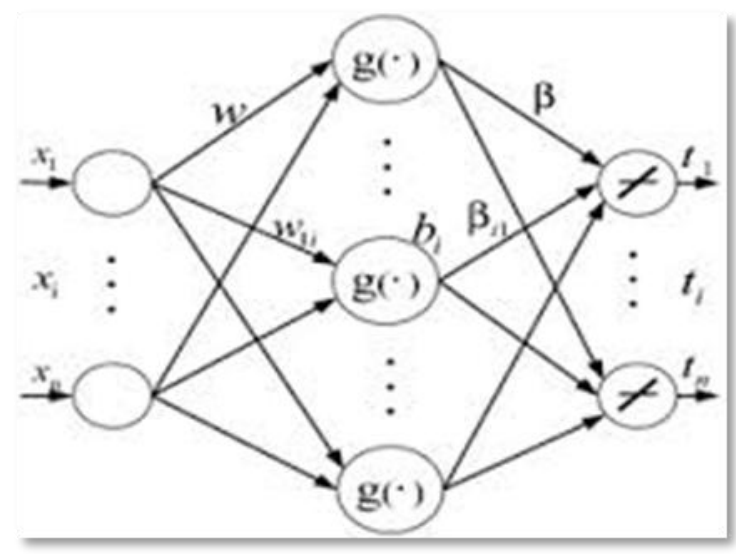

Fig. 2.ELM network

\section{Algorithm:}

Given a training set $\chi=\left\{\left(\mathrm{x}_{\mathrm{i}}, \mathrm{t}_{\mathrm{i}}\right) \mid \mathrm{x}_{\mathrm{i}} \in \mathrm{R}_{\mathrm{n}}, \mathrm{t}_{\mathrm{i}} \in \mathrm{R}_{\mathrm{m}}, \mathrm{i}=\right.$ $1,2,3 \ldots . . \mathrm{N}\}$ activation function $\mathrm{g}(\mathrm{x})$, and hidden node number $\tilde{N}$. Step 1: Randomly assign input weight $\mathrm{w}_{\mathrm{i}}$ and bias $\mathrm{b}_{\mathrm{i}}, \mathrm{i}=1$.. $\tilde{N}$. Step 2: Calculate the hidden layer output matrix $H$.

$$
\begin{aligned}
& \mathrm{H}\left(\mathrm{w}_{1}, \ldots . \mathrm{w}_{\tilde{N}}, \mathrm{~b}_{1}, \ldots \mathrm{b}_{\tilde{N}}, \mathrm{x}_{1}, \ldots \mathrm{x}_{\mathrm{N}}\right)= \\
& {\left[\begin{array}{ccc}
g(\mathrm{w} 1 . x 1+b 1) & \cdots & g(w \tilde{N} \cdot x 1+b \tilde{N}) \\
\vdots & \ddots & \vdots \\
g(w 1 . x N+b 1) & \cdots & g(w \tilde{N} . x N+b \tilde{N})
\end{array}\right] \mathrm{N} \mathrm{x} \mathrm{\tilde {N }}}
\end{aligned}
$$

Step 3: Calculate the output weight $\beta$

$$
\beta=\mathrm{H}^{+} \mathrm{T} \text {, where } \mathrm{T}=\left[\mathrm{t}_{1}, \mathrm{t}_{2}, \ldots . . \mathrm{t}_{\mathrm{N}}\right]
$$

where $\mathrm{H}^{+}$is the Moore-Penrose generalized inverse of the hidden layer output matrix.

There are several ways to calculate the Moore-Penrose generalized inverse of a matrix, including orthogonal projection method, orthogonalization method, iterative method, and singular value decomposition (SVD). The orthogonal projection method can be used when $\mathrm{H}^{\mathrm{T}} \mathrm{H}$ is nonsingular and

$$
\mathrm{H}^{+}=\left(\mathrm{H}^{\mathrm{T}} \mathrm{H}\right)^{-1}
$$
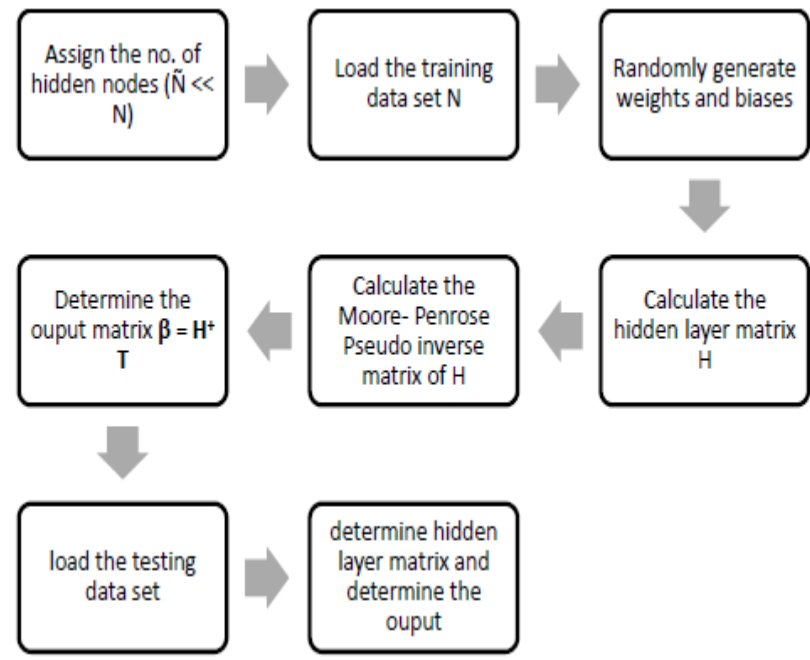

Fig. 3.Flowchart showing the ELM algorithm

However, $\mathrm{H}^{\mathrm{T}} \mathrm{H}$ may tend to become singular in some applications. Thus orthogonal projection method may not perform well in all applications. The orthogonalization method and iterative method have limitations since searching and iterations are used. The SVD can always be used to calculate the Moore-Penrose generalized inverse of $\mathrm{H}$, and thus is used in the most implementations of ELM $[2,5]$. The output matrix $\hat{\beta}$ is based on the least square solution of the given equation

$$
\begin{aligned}
& \left\|\mathrm{H}\left(\mathrm{w}_{1}, \ldots \mathrm{w}_{\tilde{N}}, \mathrm{~b}_{1}, \ldots \mathrm{b}_{\tilde{\mathrm{N}}}, \mathrm{x}_{1}, \ldots . \mathrm{x}_{\mathrm{N}}\right) \hat{\beta}-\mathrm{T}\right\|= \\
& \min \beta\left\|\mathrm{H}\left(\mathrm{w}_{1}, \ldots . \mathrm{w}_{\tilde{\mathrm{N}}}, \mathrm{b}_{1}, \ldots \mathrm{b}_{\tilde{\mathrm{N}}}, \mathrm{x}_{1}, \ldots . \mathrm{x}_{\mathrm{N}}\right) \beta-\mathrm{T}\right\| .
\end{aligned}
$$

The minimum norm least-squares solution of $H \beta=T$ is unique, which is $\widehat{\beta}=\mathbf{H}^{+} \mathbf{T}$.

The activation function $\mathrm{g}(\mathrm{x})$ used in this algorithm should be infinitely differentiable. The activation functions like sigmoid, radial basis function, sine, hard limit, cosine, exponential and many other non- regular functions which possess the infinitely differentiable property can be chosen.

The main features of the algorithm are:

1) The hidden nodes can be adaptively assigned. Always the number of hidden nodes $\tilde{N} \ll \mathrm{N}$, the input nodes. If $\tilde{N}>N$, the error obtained always be zero, which is practically not possible.

2) Random assignment of weights between the input and the hidden nodes. Since ELM is a batch learning process, all the inputs are given at the same time and random generation of weights removes the necessity to update weights. This brings down the training time.

3) ELM requires a single iteration to finish the complete training of the network. This is owing to the fact that the weights are randomly generated for every input sample and the output matrix is determined based on least square solution. The resultant output matrix gives the least error.

4) As the weights are not iteratively updated, this avoids the problem of local minimization.

5) The training time is very less when compared to SVM and ANN.

6) It has better generalization performance. With lesser number of input samples, ELM has found to give very accurate predictions. 
7) The universal approximation capability of ELM has proved that any Single layer feed forward network with additive or Radial Basis Function hidden nodes using activation functions that are continuous can universally approximate any target function in the Euclidean sub space [9].

8) ELM network follows empirical risk minimization technique.

\section{AREA OF STUDY}

Coonoor is an important taluk in the Nilgiris district located in Tamil Nadu, India. It is at an altitude of 1,850 $\mathrm{m}$ above mean sea level. Coonoor receives an average of approximately $121 \mathrm{cms}$ of rainfall during the North-east monsoon (October to December). The average temperature recorded in Coonoor is $27^{\circ} \mathrm{C}$ max and $12^{\circ} \mathrm{C}$ min for summer and $22^{\circ} \mathrm{C}$ max and $7^{\circ} \mathrm{C}$ min for winter seasons. There are 14 rain gauge stations near Coonoor, which keep a record of the amount of precipitation in this region. The transportation corridor which links Mettupalayam, Coonoor and Ooty is the life line of the people living in this mountainous region. Due to the heavy rainfall received by this region during North-east and South-west monsoon seasons, it is prone to shallow landslides which leads to loss of properties and human life. Thus rainfall prediction becomes very much essential for this region which can be used to develop landslide early warning systems.

\section{METHODS AND MATERIALS FOR DEVELOPING THE PREDICTIVE MODEL}

\section{Data sets used in this study}

Two types of data sets have been used and the rainfall prediction models are developed based on the two data sets.

1) Coonoor: Daily rainfall data recorded at Coonoor rain gauge station for the years 2004-2013, the maximum, minimum temperature of past 1 day, the relative humidity, wind speed, and cloud cover recorded at Coonoor and month are considered as input parameters. There are a total of 3643 input samples. 1200 samples are used for training the rainfall prediction models and 1443 samples are used for testing purpose. The data was collected from the India Meteorological Department, Chennai, India.

2) Coonoor Railway Station: Daily rainfall data for the years 2001-2012 recorded at the rain gauges in Coonoor railways station and 14 nearby rain gauges in and around this region. There are 4373 samples, out of which 700 are given for training the prediction model and 3673 are given for testing. The data was provided by the Public Water Department, Chennai, India.

\section{A. Coonoor Data set}

The data set contains the past 5 days rainfall, the maximum, minimum temperature of past 1 day, the relative humidity, wind speed and cloud cover. The target is the 6th day rainfall. The samples have been normalized between -1 and 1.

$\mathrm{R}$ : rainfall on the given day
$\mathrm{T}_{\max }$ : past one day's maximum temperature

$\mathrm{T}_{\min }$ : past one day's minimum temperature

RH : past one day's relative humidity

WS : past one day's wind speed

CC : past one day's cloud cover

$\mathrm{t}$ : target day

Table- I: Coonoor data set, 2004-2013

\begin{tabular}{|c|c|c|}
\hline Model & Input & $\begin{array}{c}\text { No. of } \\
\text { hidden } \\
\text { nodes }\end{array}$ \\
\hline Set 1 & $\begin{array}{l}\mathrm{R}_{\mathrm{t}-5}, \mathrm{R}_{\mathrm{t}-4}, \mathrm{R}_{\mathrm{t}-3}, \mathrm{R}_{\mathrm{t}-2}, \mathrm{R}_{\mathrm{t}-1,}, \mathrm{~T}_{\max }, \mathrm{T}_{\min }, \\
\mathrm{RH}, \mathrm{WS}, \mathrm{CC}, \mathrm{M}\end{array}$ & 9 \\
\hline Set 2 & $\mathrm{R}_{\mathrm{t}-5}, \mathrm{R}_{\mathrm{t}-4}, \mathrm{R}_{\mathrm{t}-3}, \mathrm{R}_{\mathrm{t}-2}, \mathrm{R}_{\mathrm{t}-1}$ & 4 \\
\hline $\begin{array}{l}\text { Without } \\
\mathbf{T}_{\max }\end{array}$ & $\begin{array}{l}\mathrm{R}_{\mathrm{t}-5}, \mathrm{R}_{\mathrm{t}-4}, \mathrm{R}_{\mathrm{t}-3}, \mathrm{R}_{\mathrm{t}-2}, \mathrm{R}_{\mathrm{t}-1,}, \mathrm{~T}_{\min }, \mathrm{RH}, \\
\text { WS, CC }\end{array}$ & 8 \\
\hline $\begin{array}{l}\text { Without } \\
\mathbf{T}_{\min }\end{array}$ & $\begin{array}{l}\mathrm{R}_{\mathrm{t}-5}, \mathrm{R}_{\mathrm{t}-4}, \mathrm{R}_{\mathrm{t}-3}, \mathrm{R}_{\mathrm{t}-2}, \mathrm{R}_{\mathrm{t}-1,1} \mathrm{~T}_{\max }, \mathrm{RH} \\
\text { WS, CC }\end{array}$ & 8 \\
\hline Without RH & $\begin{array}{l}\mathrm{R}_{\mathrm{t}-5}, \mathrm{R}_{\mathrm{t}-4}, \mathrm{R}_{\mathrm{t}-3}, \mathrm{R}_{\mathrm{t}-2}, \mathrm{R}_{\mathrm{t}-1,}, \mathrm{~T}_{\max }, \mathrm{T}_{\min }, \\
\text { WS, CC }\end{array}$ & 8 \\
\hline Without WS & $\begin{array}{l}\mathrm{R}_{\mathrm{t}-5}, \mathrm{R}_{\mathrm{t}-4}, \mathrm{R}_{\mathrm{t}-3}, \mathrm{R}_{\mathrm{t}-2}, \mathrm{R}_{\mathrm{t}-1,}, \mathrm{~T}_{\max }, \mathrm{T}_{\text {min }}, \\
\mathrm{RH}, \mathrm{CC}\end{array}$ & 8 \\
\hline Without CC & $\begin{array}{l}\mathrm{R}_{\mathrm{t}-5}, \mathrm{R}_{\mathrm{t}-4}, \mathrm{R}_{\mathrm{t}-3}, \mathrm{R}_{\mathrm{t}-2}, \mathrm{R}_{\mathrm{t}-1,}, \mathrm{~T}_{\max }, \mathrm{T}_{\min }, \\
\mathrm{RH}, \mathrm{WS}\end{array}$ & 8 \\
\hline Only $T_{\max }$ & $\mathrm{R}_{\mathrm{t}-5}, \mathrm{R}_{\mathrm{t}-4}, \mathrm{R}_{\mathrm{t}-3}, \mathrm{R}_{\mathrm{t}-2}, \mathrm{R}_{\mathrm{t}-1}, \mathrm{~T}_{\max }$ & 5 \\
\hline Only $T_{\text {min }}$ & $\mathrm{R}_{\mathrm{t}-5}, \mathrm{R}_{\mathrm{t}-4}, \mathrm{R}_{\mathrm{t}-3}, \mathrm{R}_{\mathrm{t}-2}, \mathrm{R}_{\mathrm{t}-1,}, \mathrm{~T}_{\min }$ & 5 \\
\hline Only RH & $\mathrm{R}_{\mathrm{t}-5}, \mathrm{R}_{\mathrm{t}-4}, \mathrm{R}_{\mathrm{t}-3}, \mathrm{R}_{\mathrm{t}-2}, \mathrm{R}_{\mathrm{t}-1,}, \mathrm{RH}$ & 5 \\
\hline Only WS & $\mathrm{R}_{\mathrm{t}-5}, \mathrm{R}_{\mathrm{t}-4}, \mathrm{R}_{\mathrm{t}-3}, \mathrm{R}_{\mathrm{t}-2}, \mathrm{R}_{\mathrm{t}-1,}, \mathrm{WS}$ & 5 \\
\hline Only CC & $\mathrm{R}_{\mathrm{t}-5}, \mathrm{R}_{\mathrm{t}-4}, \mathrm{R}_{\mathrm{t}-3}, \mathrm{R}_{\mathrm{t}-2}, \mathrm{R}_{\mathrm{t}-1, \mathrm{CC}}$ & 5 \\
\hline
\end{tabular}

\section{B. Coonoor Railways data set}

This data set consists of 5 days antecedent rainfall recorded at Coonoor railways rain gauge station (t-1 to $\mathrm{t}-5$ ), rainfall data of Coonoor, Runny Medu, Kethi, average rainfall data of Ooty, SCR Ooty and Kothagiri, average rainfall data of all 14 rain gauge stations close to Coonoor railways rain gauge station and Month. The 6th day $(\mathrm{t})$ rainfall has to be predicted. The samples have been normalized between -1 and 1 .

$\mathrm{R}$ : Rainfall on a given day

$\mathrm{X}$ : Rainfall Data recorded at Coonoor

Y : Rainfall Data recorded at Runny Medu

$\mathrm{Z}$ : Rainfall Data recorded at Kethi

$\mathrm{P}$ : Average of rainfall recorded at Ooty, SCR Ooty and Kothagiri

$\mathrm{S}$ : Average of the rainfall data recorded at all rain gauge stations

M: Month

$\mathrm{t}$ : target day

Table- II: Coonoor Railways data set 2001-2012

\begin{tabular}{|l|l|c|}
\hline \multicolumn{1}{|c|}{ Model } & \multicolumn{1}{|c|}{ Input } & $\begin{array}{c}\text { No. of } \\
\text { hidden } \\
\text { nodes }\end{array}$ \\
\hline Set 1 & $\begin{array}{l}\mathrm{R}_{\mathrm{t}-5}, \mathrm{R}_{\mathrm{t}-4}, \mathrm{R}_{\mathrm{t}-3}, \mathrm{R}_{\mathrm{t}-2}, \mathrm{R}_{\mathrm{t}-1}, \mathrm{X}_{\mathrm{t}-1}, \mathrm{Y}_{\mathrm{t}-1}, \\
\mathrm{Z}_{\mathrm{t}-1}, \mathrm{M}_{\mathrm{t}-1}\end{array}$ & 8 \\
\hline Set 2 & $\mathrm{R}_{\mathrm{t}-5}, \mathrm{R}_{\mathrm{t}-4}, \mathrm{R}_{\mathrm{t}-3}, \mathrm{R}_{\mathrm{t}-2}, \mathrm{R}_{\mathrm{t}-1}, \mathrm{P}_{\mathrm{t}-1}, \mathrm{M}_{\mathrm{t}-1}$ & 6 \\
\hline Set 3 & $\mathrm{R}_{\mathrm{t}-5}, \mathrm{R}_{\mathrm{t}-4}, \mathrm{R}_{\mathrm{t}-3}, \mathrm{R}_{\mathrm{t}-2}, \mathrm{R}_{\mathrm{t}-1}, \mathrm{~S}_{\mathrm{t}-1}, \mathrm{M}_{\mathrm{t}-1}$ & 6 \\
\hline Set $\mathbf{4}$ & $\mathrm{R}_{\mathrm{t}-5}, \mathrm{R}_{\mathrm{t}-4}, \mathrm{R}_{\mathrm{t}-3}, \mathrm{R}_{\mathrm{t}-2}, \mathrm{R}_{\mathrm{t}-1}, \mathrm{X}_{\mathrm{t}-1}, \mathrm{Y}_{\mathrm{t}-1}$, & 10 \\
\hline
\end{tabular}




\section{Rainfall Prediction using Extreme Learning Machine for Coonoor Region}

Table- III: Sensitivity Analysis

\begin{tabular}{|c|l|c|}
\hline Model & Input & $\begin{array}{c}\text { No. of } \\
\text { hidden } \\
\text { nodes }\end{array}$ \\
\hline $\mathbf{X}$ & Rt-5, Rt-4, Rt-3, Rt-2, Rt-1, Xt-1 & 5 \\
\hline $\mathbf{Y}$ & Rt-5, Rt-4, Rt-3, Rt-2, Rt-1, Yt-1 & 5 \\
\hline $\mathbf{Z}$ & Rt-5, Rt-4, Rt-3, Rt-2, Rt-1, Zt-1 & 5 \\
\hline $\mathbf{X , Y}$ & Rt-5, Rt-4, Rt-3, Rt-2, Rt-1, Xt-1, Yt-1 & 6 \\
\hline $\mathbf{X , Z}$ & Rt-5, Rt-4, Rt-3, Rt-2, Rt-1, Xt-1, Zt-1 & 6 \\
\hline Y,Z & Rt-5, Rt-4, Rt-3, Rt-2, Rt-1, Yt-1, Zt-1 & 6 \\
\hline $\mathbf{P}$ & Rt-5, Rt-4, Rt-3, Rt-2, Rt-1, Pt-1 & 5 \\
\hline S & Rt-5, Rt-4, Rt-3, Rt-2, Rt-1, St-1 & 5 \\
\hline $\mathbf{M}$ & Rt-5, Rt-4, Rt-3, Rt-2, Rt-1, Mt-1 & 5 \\
\hline
\end{tabular}

The rainfall prediction models shown in Table I and II have been developed to determine if only rainfall as input parameter can increase the accuracy. From this data set we can also determine the network's capability to handle large input samples, with lesser training data. The algorithm has been implemented using MATLAB 2013. Sigmoidal activation function has been used to obtain the results.

Sensitivity analysis has been carried out using the prediction models given in Table III to determine the most important predictor that contributes to accurate prediction of rainfall.

\section{Performance Measures}

The performance parameters chosen are Root Mean Square Error, Correlation Coefficient and Training Time.

1) Root Mean Square Error (RMSE):

It is the standard deviation of the difference between the predicted and actual values.

$$
\mathrm{RMSE}=\sqrt{\frac{1}{n} \sum_{1}^{n}(y-x)^{2}}
$$

Where, $\mathrm{n}=$ number of training/ testing samples

$\mathrm{y}=$ predicted output; $\mathrm{x}=$ desired output

2) Pearson Correlation Coefficient $(C C)$ :

It is the measure of linear dependence between two variables. The value of $\mathrm{CC}$ ranges between -1 and $1 .-1$ indicates negative correlation, 0 , no correlation and 1 , positive correlation.

$$
\begin{gathered}
S_{x x}=\sum x^{2}-\left(\sum x^{2}\right) / n \\
S_{y y}=\sum y^{2}-\left(\sum y^{2}\right) / n \\
\mathrm{~S}_{x y}=\sum x y-\left(\sum x \cdot \sum y\right) / n \\
C C=\frac{s_{x y}}{\sqrt{s_{x x} \cdot s_{y y}}}
\end{gathered}
$$

\section{3) Training time (TT)}

The time taken to train the network is recorded. The training time should be less for real time applications.

\section{RESULTS AND DISCUSSIONS}

From Table IV it can be seen that while working with the prediction model - Set 1, where the number of input parameters is large when compared to other models, the accuracy has not improved. Thus it can be said that not all the input predictors are necessary for prediction. The best results are obtained for when only the past 5 days rainfall data is

used, or past 5 days rainfall with either Tmax, or Tmin, or wind speed or relative humidity. The correlation coefficient is highest in case of Set 2. Thus it can be concluded that only rainfall data is sufficient to predict rainfall in the region.

However it can also be concluded that maximum temperature is one of the important predictors and greatly influences the rainfall pattern. It is clear from the Table IV that there is not much significant change in the error obtained in various models, this can be attributed to the excellent generalization performance of ELM.

Table- IV: Coonoor data set, TT: training time

\begin{tabular}{|l|c|c|c|c|}
\hline \multicolumn{1}{|c|}{ Model } & MSE & RMSE & CC & TT(sec) \\
\hline Set 1 & 0.0022 & 0.0469 & 0.3773 & 0.0624 \\
\hline Set 2 & 0.002 & 0.0447 & 0.4799 & 0.0468 \\
\hline $\begin{array}{l}\text { Without } \\
\mathbf{T}_{\max }\end{array}$ & 0.0021 & 0.0458 & 0.4112 & 0.0156 \\
\hline $\begin{array}{l}\text { Without } \\
\mathbf{T}_{\min }\end{array}$ & 0.0021 & 0.0458 & 0.4052 & 0.0312 \\
\hline $\begin{array}{l}\text { Without } \\
\text { RH }\end{array}$ & 0.0022 & 0.0469 & 0.3481 & 0.0312 \\
\hline $\begin{array}{l}\text { Without } \\
\text { WS }\end{array}$ & 0.0022 & 0.0469 & 0.3289 & 0.0312 \\
\hline $\begin{array}{l}\text { Without } \\
\text { CC }\end{array}$ & 0.0021 & 0.0458 & 0.4099 & 0.0312 \\
\hline Only Tmax & 0.002 & 0.0447 & 0.4519 & 0.0312 \\
\hline Only Tmin & 0.002 & 0.0447 & 0.4419 & 0.0624 \\
\hline Only RH & 0.002 & 0.00447 & 0.4389 & 0.0312 \\
\hline Only WS & 0.002 & 0.0447 & 0.4316 & 0.0312 \\
\hline Only CC & 0.0021 & 0.0458 & 0.4158 & 0.0312 \\
\hline
\end{tabular}

Table- V:Coonoor Railways Data Set

\begin{tabular}{|l|c|c|c|c|}
\hline \multicolumn{1}{|c|}{ Model } & MSE & RMSE & CC & TT(sec) \\
\hline Set 1 & 0.0016 & 0.04 & 0.2727 & 0.0936 \\
\hline Set 2 & 0.0016 & 0.04 & 0.3051 & 0.0312 \\
\hline Set 3 & 0.0015 & 0.03872 & 0.3174 & 0.0624 \\
\hline Set 4 & 0.0017 & 0.04123 & 0.1222 & 0.0312 \\
\hline $\mathbf{X}$ & 0.0016 & 0.04 & 0.3023 & 0.0624 \\
\hline $\mathbf{Y}$ & 0.0016 & 0.04 & 0.2958 & 0.0312 \\
\hline $\mathbf{Z}$ & 0.0016 & 0.04 & 0.3246 & 0.0312 \\
\hline $\mathbf{X , Y}$ & 0.0016 & 0.04 & 0.2988 & 0.0156 \\
\hline $\mathbf{Y , Z}$ & 0.0016 & 0.04 & 0.3082 & 0.0312 \\
\hline $\mathbf{P}$ & 0.0016 & 0.04 & 0.3061 & 0.0312 \\
\hline S & 0.0016 & 0.04 & 0.3068 & 0.0312 \\
\hline $\mathbf{M}$ & 0.0016 & 0.04 & 0.3150 & 0.0312 \\
\hline
\end{tabular}

From Table V, it can be seen that set 3 has the least RMSE. Thus it can be concluded that the input predictor ' $S$ ', the average rainfall data of all the stations and antecedent rainfall for past 5 days recorded at Coonoor railway rain gauge station, are the best predictors in predicting rainfall in this location. The accuracy obtained when all the predictors are rainfall values is very high. Thus it can be conclusively shown that only rainfall data can be an excellent predictor. This was also proved from the results obtained by Coonoor data set. Similar work was done by [8], 
where it was shown that only rainfall data performed very well with an 11 hidden node BP network. 700 input samples were given to the network for training and the accuracy obtained is very high, this is much better than other SLFN based models which require a large training data set and can take several minutes to several hours to train the network.

From the correlation coefficient values obtained for various models it can be seen that rainfall data of Coonoor has significantly contributed to the predicted output. This is because Coonoor is the closest place to our area of interest.

From Fig. 4, it is seen that the desired and the predicted rainfall does not closely follow each other for Coonoor data set 1. In Fig. 5, the desired and the predicted rainfall of Coonoor data set 2 is comparatively better than that shown in Fig. 4. From these results it is clearly shown that only rainfall data is sufficient to predict rainfall.

Fig. 6 shows the comparison between the desired and the predicted rainfall of the coonoor data set model with only temperature as the additional parameter along with past 5 days rainfall data. In Fig. 7, the performance of coonoor railways data set 3 model is shown. The prediction model gives a good result, except on the days where unusually heavy rainfall had been recorded. The sensitivity analysis results of the same model is shown in Fig. 8.

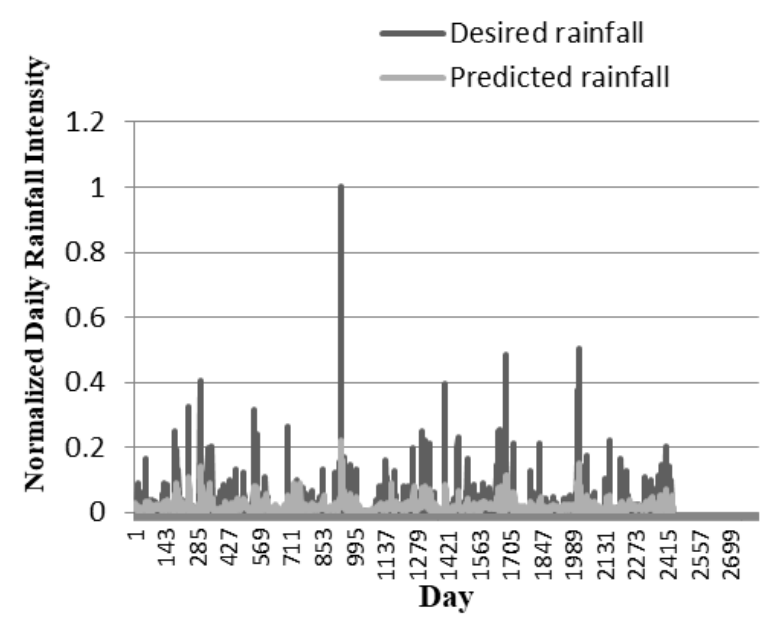

Fig. 4.Coonoor data set1

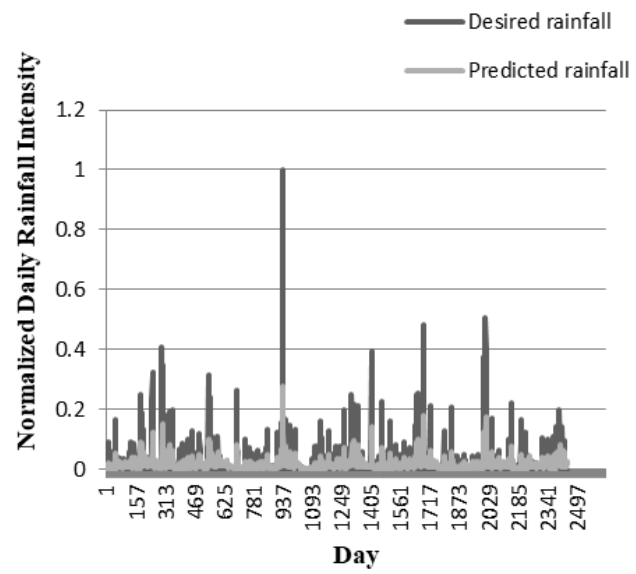

Fig. 5.Coonoor data set 2

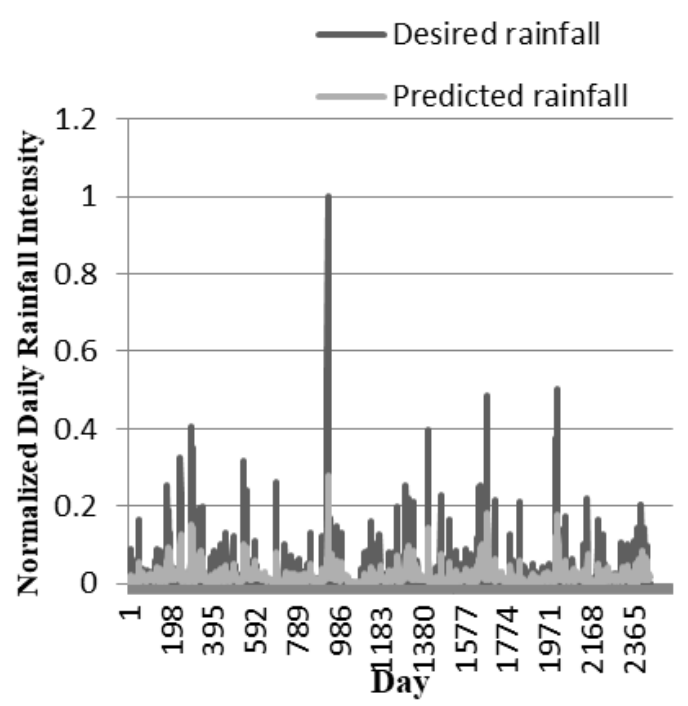

Fig. 6.Coonoor data set with only Tmax

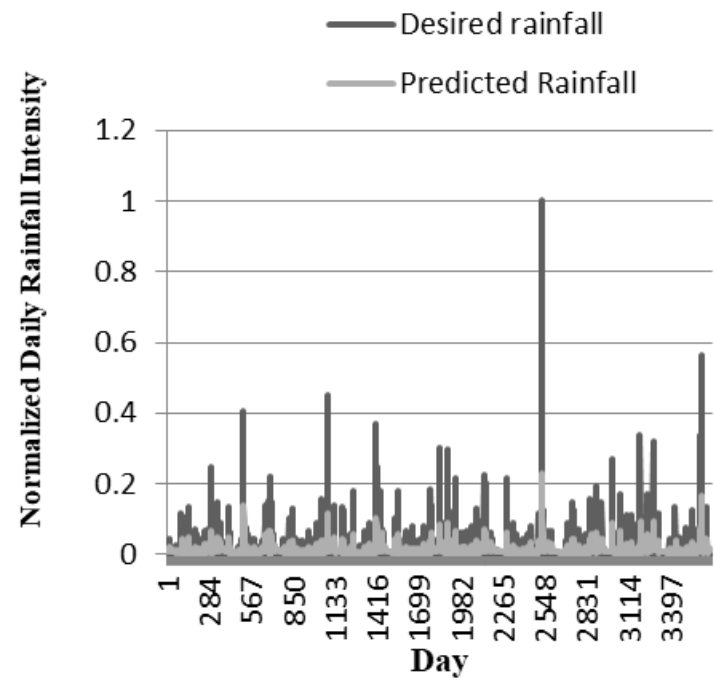

Fig. 7.Coonoor Railways data set, input set 3

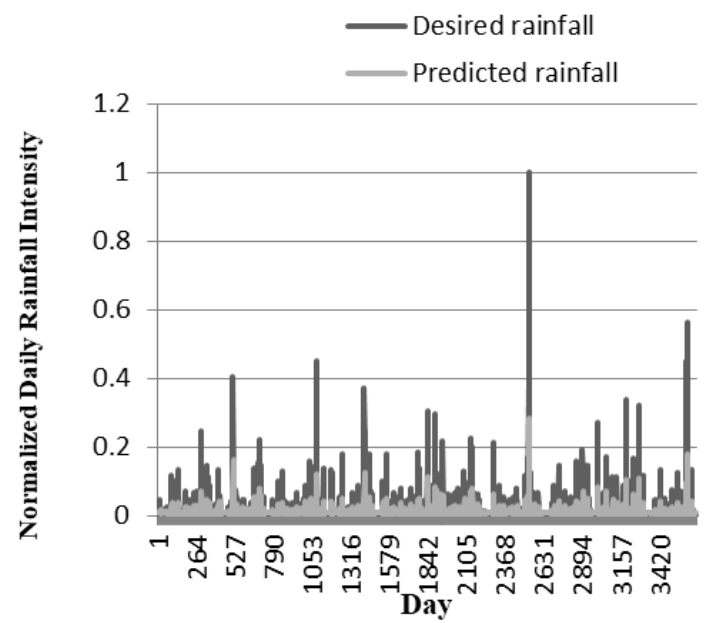

Fig. 8. Coonoor railways sensitivity analysis, Average of all 14 stations 


\section{Rainfall Prediction using Extreme Learning Machine for Coonoor Region}

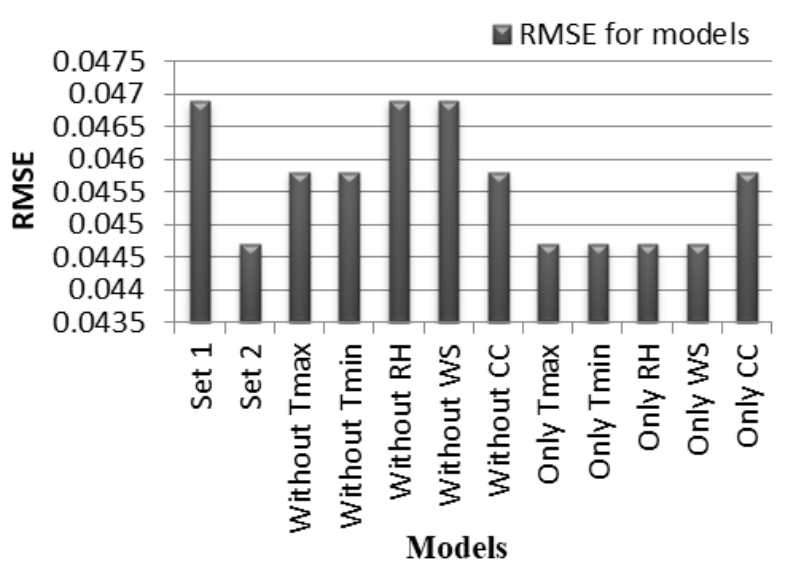

Fig. 9.RMSE for the various models developed for the Coonoor data set (2004-2013)

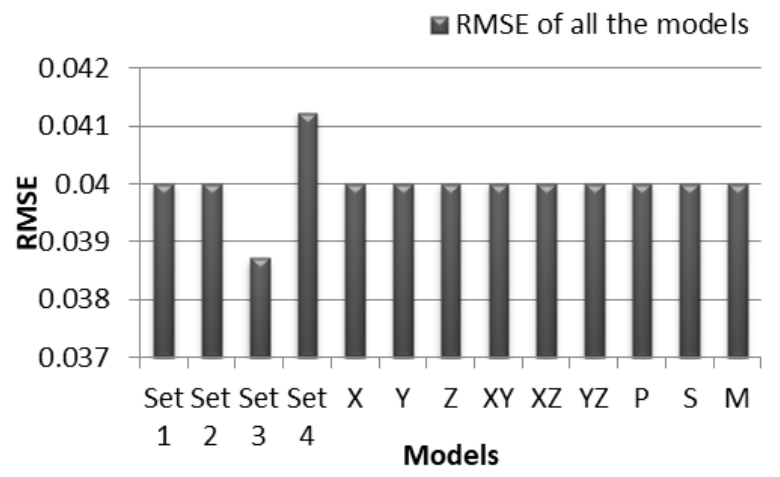

Fig. 10.RMSE for the various models developed for the Coonoor Railways data set (2001-2012)

Fig. 9 and 10 show the RMSE plots for the various models developed. From the plots we can clearly observe that there is not much variation in RMSE obtained, thus the type of input predictor and the number of input predictor do not greatly influence the predicted output.

\section{CONCLUSIONS}

The study focused on the development of a daily rainfall prediction system for Coonoor region by developing various models using Extreme Learning Machine. The tables and graphs conclude the following:

1) For the Coonoor region data set, it is established that maximum temperature of past one day is the most important predictor. However we obtain good results for only rainfall as the input predictors also.

2) For the Coonoor railways data set, it is concluded that the past 5 days rainfall intensity recorded by the rain gauge station in Coonoor railway and the average of the rainfall intensity recorded in the 14 rain gauge stations located in the viscinity of Coonoor railway, result in the best predicted output for the $6^{\text {th }}$ day rainfall. On performing sensitivity analysis, average of all the 14 stations is found to be the most important input predictor. Month as an input predictor deteriorates the results, thus month can be ignored in this case.

The two data sets have justified the importance of other meteorological parameters and rainfall intensities of the surrounding regions in predicting rainfall accurately in a given region. Thus, the meteorological parameters are advantageous but not prime essential for predicting rainfall. Sensitivity analysis not only validates the same but also opens the door for rainfall intensities of nearby regions to be included in the task of forecasting. The paper thus concludes the ELM does possess a very strong capability to predict rainfall in the absence of meteorological parameters.

\section{ACKNOWLEDGEMENT}

Rainfall data used in this study was procured from India Meteorological Department (IMD), Chennai, India and Public Works Department, Chennai, India.

\section{REFERENCES}

1. G. B. Huang, L. Chen, and C. K. Siew, "Universal approximation using incremental networks with random hidden computation nodes, " IEEE Trans. Neural Networks, vol. 17, 2006.

2. H. Aksoy, A. Guven, A. Aytek, M. Yuce and N. E. Unal, "Discussion of generalized regression neural networks for evapotranspiration modelling," Hydrol. Sci. J., vol. 52, pp. 825-828, 2007.

3. D. Koutsoyiannis, "Discussion of "'generalized regression neural networks for evapotranspiration modelling,' Hydrol. Sci. J., vol. 52, pp 832-835, 2007

4. S. Ding, H. Zhao, Y. Zhang, X. Xu, and R. Nie, "Extreme learning machine: algorithm, theory and applications," Artificial Intelligence Review, pp. 1-13, 2013.

5. S. Yu, C. Miao, and X. Wang, "Application of extreme learning machine neural network to forecast of short-term precipitation," Journal of Yunnan University, 2013.

6. R. Singh, S. Balasundaram, "Application of Extreme Learning Machine Method for Time Series Analysis," Intl. J. of Intelligent Technology, Vol.2, No.4, pp. 256-262, 2007.

7. S. Chattopadhyay, and G. Chattopadhyay, "Identification of the best hidden layer size for three layered neural net in predicting monsoon rainfall in India," J. of Hydroinformatics, 2008.

8. Z. Sun, T. S. Choi, K. Au, and Y. Yu, "Sales forecasting using extreme learning machine with applications in fashion retailing," Decision Support System, 2008.

9. W. Zong, G. B. Huang, "Face recognition based on extreme learning machine," J. of Neurocomputing, 2011.

\section{AUTHORS PROFILE}

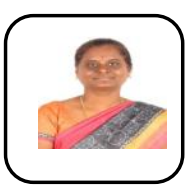

S. Renuga Devi, received her Ph.D degree from Vellore Institute of Technology, India. She has a bachelor's degree in Electronics and Communication Engineering and Master's degree in Applied Electronics from Bharathiar University,India. Currently she is working as Associate Professor in the School of Electronics Engineering, Vellore Institute of Technology, India. She has published technical papers in national and international journals and conferences. Her research interest includes Machine learning, Artificial Intelligence and its Applications, Wireless Sensor Networks and Wireless communication. She is a life member of ISTE. 